\title{
Akciğer Nakil Adaylarında Egzersiz Kapasitesinin Periferik Kas Kuvveti ve Solunum Fonksiyonları ile iliş̧kisi
}

\author{
Esra Pehlivan*, Sevda Boyacı Kalafat, Arif Balcı, Lütfiye Kılıç
}

\section{DOI: $10.17944 /$ mkutfd. 538403}

Esra Pehlivan: Dr. Öğr. Üyesi, Sağık Bilimleri Üniversitesi Hamidiye Sağlık Bilimleri Fakültesi Fizyoterapi ve Rehabilitasyon Bölümü, İstanbul Email: fztesrakambur@yahoo.com ORCID iD: https://orcid.org/0000-0002-1791-5392

Sevda Boyacı Kalafat: Diyetisyen, Mardin Devlet Hastanesi, Mardin

Email: dytsevdaboyaci@hotmail.com

ORCID iD: https://orcid.org/0000-0002-5010-7469

Arif Balcı: Fizyoterapist, Sağlık Bilimleri Üniversitesi Yedikule Göğüs Hastalıkları ve Göğüs Cerrahisi Eğitim ve Araștırma Hastanesi, İstanbul Email: arifbalci2000@yahoo.com ORCID iD: https://orcid.org/0000-0002-4052-3506

Lütfiye Kılıc: Uzm. Dr., Sağlık Bilimleri Üniversitesi Yedikule Göğüs Hastalıkları ve Göğüs Cerrahisi Eğitim ve Araștırma Hastanesi, İstanbul Email: lutuf1@yahoo.com

ORCID iD: https://orcid.org/0000-0002-5609-0522

\section{Bildirimler/Acknowledgements}

Yazarlar bu makale ile ilgili herhangi bir çıkar çatıșması bildirmemișlerdir.

The authors declare that they have no conflict of interests regarding content of this article.

Yazarlar bu makale ile ilgili herhangi bir finansal destek bildirmemișlerdir.

The Authors report no financial support regarding content of this article.

$\therefore$ Sorumlu Yazar/Corresponding Author

Geliș/Received: 11.03 .2019

Kabul/Accepted: 05.08.2019

e-ISSN: 2149-3103

Web: https://dergipark.org.tr/mkutfd
Öz

Akciğer Nakil Adaylarında Egzersiz Kapasitesinin Periferik Kas Kuvveti ve Solunum Fonksiyonları ile iliş̧kisi

Amaç: Çalıșmamızda akciğer nakil adaylarında fonksiyonel egzersiz kapasitesi seviyesinin, periferik kas gücü ve solunum fonksiyonları ile olan ilișkisini incelemeyi amaçladık.

Gereç ve Yöntem: Hastanemiz pulmoner rehabilitasyon merkezinde, akciğer nakli öncesi rehabilitasyon programına alınması için refere edilen 25 hasta çalıșmaya dahil edildi. Hastalar 6 -dakika yürüyüș testi yürüme mesafelerine (6DYM) göre 2 gruba ayrıldı (Grup1: 6DYM<350m, n:14; Grup2: 6DYM350m, n=11). Grupların kas ve yağ kütle ve yüzdeleri, periferik kas kuvvetleri karșılaștıılldı, egzersiz kapasitesi seviyesinin kas kütlesi ve solunum fonksiyonları ile olan ilișkisi incelendi.

Bulgular: Gruplar benzer demografik özelliklere sahipti (yaș, beden kitle indeksi). Kas kütleleri ( $p=, 956)$, yağsız doku yüzdeleri $(p=, 956)$, yağ kütleleri $(p=, 827)$ ve vücut yağ yüzdeleri $(p=, 701)$ benzerdi. Periferik kas kuvvetleri karșılaștırıldığında diz ekstansiyonu, dirsek fleksiyonu ve el kavrama kuvvetleri benzer olup, Grup1'in dorsifleksiyon kas kuvvetinin $(p=, 039)$ ve FEV1\% $(p=0,033)$ değerlerinin istatistiksel olarak daha düșük olduğu tespit edildi. 6DYM ile diğer sonuç ölçümleri arasında yapılan ilișki analizinde dirsek fleksiyonu ( $r=, 483 ; p=, 015)$, dorsifleksiyon ( $r=, 518$; $p=, 008)$ kas kuvveti ve FEV1\% $(r=, 514 ; p=, 009)$ ile orta, FVC\% $(r=, 605 ; p=, 001)$ ile ise yüksek seviyede korelasyon tespit edildi.

Sonuç: Çalıșmamızdaki akciğer nakil adayı olan hastaların egzersiz kapasiteleri, kas ve yağ kütlesinden bağımsız olup, kas kuvvetinden ve solunum fonksiyonlarından etkilenmektedir. Bu durum, bu hasta grubunda egzersiz kapasitesindeki azalmanın daha ziyade primer akciğer patolojisine bağlı olduğunu düșündürmektedir. Daha anlamlı sonuçların elde edilebilmesi için, rehabilitasyon sonrası değișimler incelenmelidir.

Anahtar Kelimeler: akciğer transplantasyonu, fizyoterapi, kas kuvveti, egzersiz, rehabilitasyon

\section{Abstract}

The Relationship of Exercise Capacity with Peripheral Muscle Strength and Lung Functions in Lung Transplantation Candidates

Aim: We aimed to investigate the relationship between functional exercise capacity level and muscle strength and lung functions in the lung transplantation (LTX) candidates.

Materials and Methods: Twenty-five patients who were referred to our hospital for the pre-transplantation pulmonary rehabilitation program were included in the study. Patients were divided into 2 groups according to the 6-min walk test walking distance (Group1: 6MWD<350m; n:14, Group2: 6DWD $\geq 350 \mathrm{~m}, \mathrm{n}=11$ ). The percentage of muscle and fat masses, peripheral muscle forces were compared and the relationship between the muscle mass, muscle strength, lung functions and the exercise capacity level were examined.

Results: The groups have similar demographic characteristics (age, body mass index). Muscle masses ( $p=.956)$, lean tissue ( $p=.956)$, fat masses $(p=.827)$, fat percentages $(p=.701)$ were similar. When the peripheral muscle strengths were compared, the knee extension, elbow flexion and hand grip strengths were similar, and the dorsiflexion muscle strength $(p=.039)$ and FEV1\% $(p=0.030)$ values of group 1 were found to be statistically low. The correlation between 6MWD and other outcome measures, there were moderate correlation with elbow flexion $(r=.483 ; p=.015)$, dorsiflexion ( $r=.518 ; p=.008)$ and \%FEV1 ( $r=.514 ; p=.009)$ and high level correlation with \%FVC ( $r=.605 ; p=.001)$. Conclusion: In our study, the exercise capacities of LTx candidates are independent of muscle and fat mass and are influenced by muscle strength and lung functions. This suggests that exercise capacity is related to primary lung pathology in this patient group. In order to obtain more meaningful results, post-rehabilitation changes should be examined.

Keywords: lung transplantation, physiotherapy, muscle strength, exercise, rehabilitation 


\section{GİRIŞ̧}

Akciğer nakli, kronik obstruktif akciğer hastalığı $(\mathrm{KOAH})$, kistik fibrozis, idiopatik pulmoner fibrozis ve pulmoner hipertansiyon gibi farklı akciğer patolojilerinde sağ kalımı uzatmak amacıyla yapılan cerrahi bir işlemdir (1).

Pulmoner Rehabilitasyon (PR), kronik solunum hastalığı olan bireylerde ayrıntılı hasta değerlendirmesi ve bunu takip eden, hastaya özel terapileri temel alan, sadece egzersiz, eğitim ve davranışsal değişiklikleri değil aynı zamanda bireylerin fiziksel ve psikolojik durumlarını geliştirmek üzere oluşturulmuş kapsamlı bir müdahaledir (2). Bu çok kapsamlı müdahalenin en önemli komponenti egzersizdir. Egzersiz performansı ile ilişkili veriler, programın oluşturulmasında ve etkinliğinin değerlendirilmesinde sıklıkla kullanılmaktadır. Egzersiz kapasitesinin değerlendirilmesinde kullanılan testlemelerin başında 6 -dakika yürüyüş testi gelmektedir.

Akciğer nakli için listelenmiş olan terminal dönem solunum hasta grubunda egzersiz kapasitesi son derece k1sıtlıdır (3). Literatürde egzersiz kapasitesinin azalışı farklı mekanizmalarla açıklanmaya çalışılmaktadır (4). Akciğer nakli sonrasında egzersiz kapasitesinin yavaş geri dönüşü, periferik kas kuvveti gibi farklı mekanizmaların da bu durumda etkili olabileceğini düşündürmektedir (5). Çalışmamızın amacı akciğer nakil adaylarında fonksiyonel egzersiz kapasitesi seviyesinin, periferik kas kuvveti ve solunum fonksiyonları ile olan ilișkisinin belirlenmesidir. Bu ilişkinin belirlenmesinin egzersiz programlarının oluşturulmasinda yol gösterici olacağı kanaatindeyiz.

\section{GEREÇ VE YÖNTEM}

Çalışmamıza Ağustos 2017- Ocak 2019 tarihleri arasında akciğer nakli bekleme listesinde bulunan ve PR programına alınması ise tarafımıza yönlendirilen hastalar retrospektif olarak çalışmaya dahil edildi. Altı dakika yürüyüş testi yürüme mesafesi baz alınarak, 350 metre eşik değer olarak kabul edildi ve iki grup oluşturuldu. 350 metrenin eşik değer olarak kabul edilmesinin nedeni, akciğer nakil adaylarının belirlenmesinde BODE indeksinin yaygın olarak kullanılması ve indekste 350 metrenin eşik değer olarak kullanılmasıdır (6,7). 350 metrenin altında yürüme mesafesine sahip olan olgular Grup 1; 350 metre ve üstünde yürüme mesafesine sahip olan olgular ise Grup 2 olarak adlandırıldı. Grupların çalışma sonuç ölçümleri karşılaştırıldı ve 6-dakika yürüme mesafesi ile diğer sonuç ölçülerinin ilişkileri incelendi.

Çalışmamıza Yerel Üniversite Etik Kurulu tarafından 01.02.19 tarih ve 1666 sayı ile etik kurul onayı alındı. Çalışma Helsinki Deklerasyonu'na uygun olarak gerçekleştirildi.

\section{Çalışma sonuç ölçümleri}

Altı Dakika Yürüyüş Testi: Test 30 metrelik düz bir koridorda klavuzlara uygun olarak gerçekleștirildi. Test öncesi ve sonrasında oksijen saturasyonu, kalp hızı, Borg yorgunluk puanı ve yürüme mesafesi kaydedildi.

Solunum Fonksiyon Testi: Test Sensor Medics model 2400 (Yorba Linda, CA, USA) spirometri kullanılarak American Thoracic Society (ATS) klavuzuna uygun olarak yapıldı.

Periferik Kas Kuvvet Ölçümü: Hastanın kavrama kuvveti (Handgrip) ölçümleri gerçekleştirildi. Üst ve alt ekstremite kas gücü ölçümü dijital dinamometre kullanılarak (J-Tech Commander muscle testing cihazı) majör kaslara yapıldı. Her ölçüm sağ ve sol ekstremiteye üçer tekrarlı olarak uyguland.

Biyoelektrik Empedans Analizi: Biyoelektrik empedans analizi ölçümü “TANİTA - BC 418 MA (Tanita Corporation, Tokyo-Japonya) cihazı ile yapıldı. Ölçümler her gönüllü için yaklaşık 1-2 dakika kadar sürmüş olup, biyoelektrik empedans analiz cihazı ile saptanan değerler cihazdan çıktı olarak alındı. Biyoelektrik empedans analiz cihazından alınan çıktı üzerinde bulunan; vücut ağırlığı, beden kitle indeksi, vücut yağ yüzdesi, vücut yağ kitlesi, yağsız vücut kitlesi ve toplam vücut suyu ölçüm verileri değerlendirilmek üzere kaydedildi.

\section{İstatistiksel analiz}

İstatistiksel analiz SPSS istatistiksel paket programı (Statistical Package for Social Sciences Version IBM Statistic 15,0. Chicago, IL, USA) kullanılarak yapıldı. Verilerin normal dağılımlarının tespitinde Shapiro Wilk test, parametrelerin kendi içindeki değişimlerinin analizinde ise Man-Whitney U Testi kullanıldı. Altı dakika yürüyüş mesafesi ve diğer klinik parametreler arasındaki ilişki analizi ise Pearson korelasyon analizi ile gerçekleştirildi. Değişkenler sayı (yüzde) ve median (minimum-maksimum) şeklinde yazıldı. $p<0,05$ istatistiksel olarak anlamlı olarak kabul edildi.

\section{BULGULAR}

Çalışmaya \%64'ü $(\mathrm{n}=16)$ erkek, yaş ortalaması $36.48 \pm 15,40$ ve beden kitle indeksi $21,20 \pm 6,47$ olan 25 hasta dahil edildi. Hastaların tamamı terminal dönem akciğer hastası olup, hepsi ek oksijen desteği almaktaydı. Grupların kas kütleleri ( $\mathrm{p}=, 956)$, yağsız doku yüzdeleri $(\mathrm{p}=, 956)$, yağ kütleleri $(\mathrm{p}=, 827)$ ve vücut yağ yüzdeleri $(\mathrm{p}=, 701)$ benzerdi. Periferik kas kuvvetleri karşılaştırıldığında diz ekstansiyonu, dirsek fleksiyonu ve hand grip kavrama kuvvetleri benzer olup, Grupl'in ayak dorsifleksiyon kas kuvvetinin $(p=, 039)$ ve $F_{1} \%(p=0,033)$ değerlerinin istatistiksel olarak daha düşük olduğu tespit edildi. Hasta gruplarının demografik özellikleri, tanı dağılımları, biyoelektrik empedans ölçüm sonuçları, kas kuvveti ölçümleri Tablo l'de verildi. 


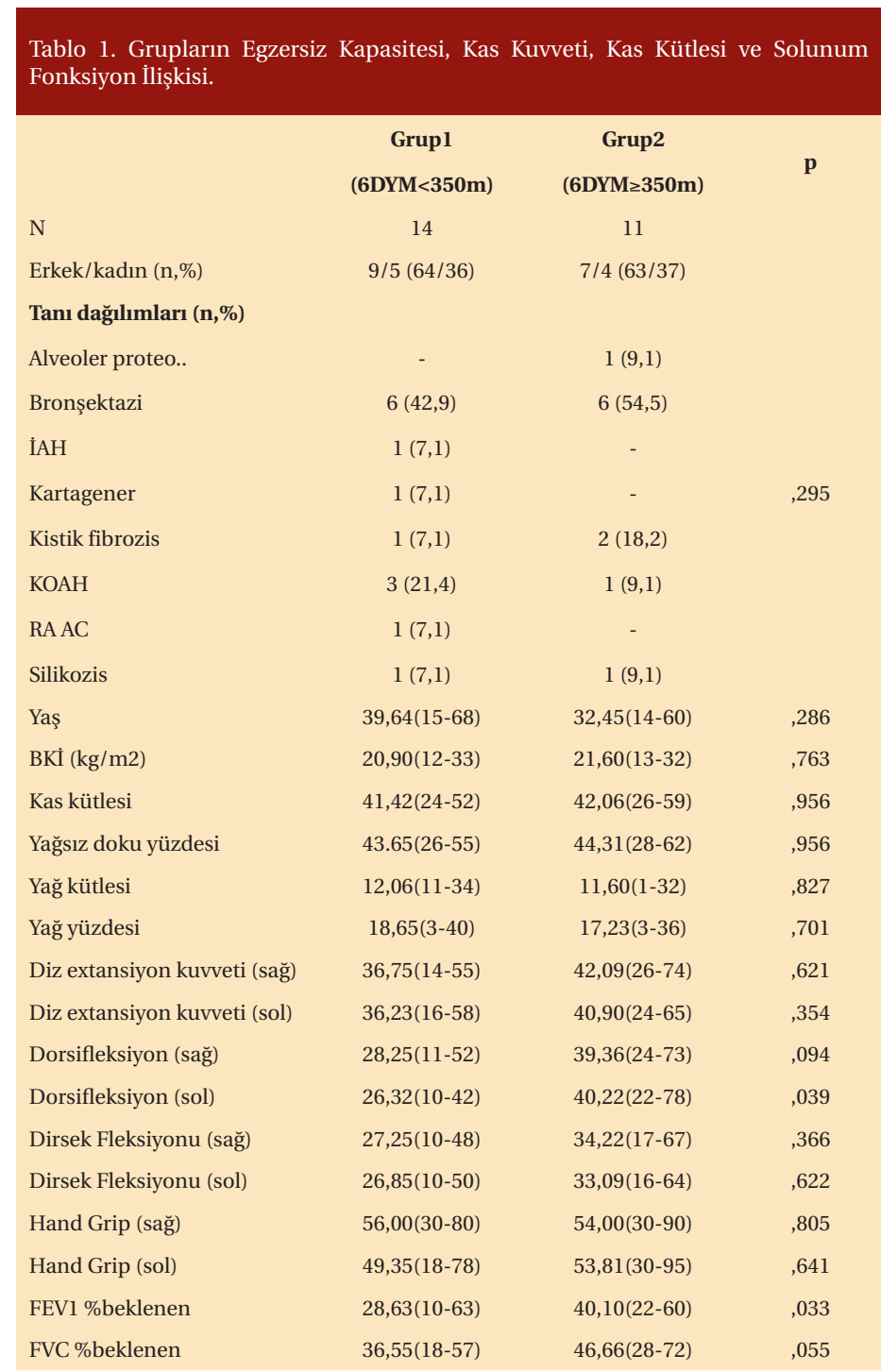

Kısaltmalar: BKI: beden kitle indeksi; FEV1: 1.saniyedeki ekspiratuar volüm; FVC: Zorlu vital kapasite; İAH: İntersisyel akciğer hastalığı; KOAH: Kronik obstruktif akciğer hastalığı; RA AC: Romatoid artrit akciğer tutulumu. Veriler sayı (yüzde) veya ortanca(minimum-maksimum) olarak verilmiştir.

Altı dakika yürüme mesafesi ile diğer çalışma sonuç ölçümleri arasında yapılan ilişki analizinde dirsek fleksiyonu $(\mathrm{r}=, 483 ; \mathrm{p}=, 015)$, dorsifleksiyon $(\mathrm{r}=, 518 ; \mathrm{p}=, 008)$ kas kuvveti ve $\mathrm{FEV}_{1} \%(\mathrm{r}=, 514 ; \mathrm{p}=, 009)$ arasinda orta seviyede, $\mathrm{FVC} \%$ $(\mathrm{r}=, 605 ; \mathrm{p}=, 001)$ ile ise yüksek seviyede korelasyon tespit edildi. Korelasyon analizi sonuçları Tablo 2'de verildi.

\section{TARTIŞMA}

Solunum hasta grubunda egzersiz kapasitesini sınırlandıran pek çok neden bulunmaktadır. Literatürde bu konu tam olarak açıklığa kavuşturulmamış olmakla birlikte; solunumsal, kardiyak faktörler ve periferal kasların oksidatif kapasitesindeki etkilenmeyle ilişkili olan periferal faktör- lerin etkili olabileceği bildirilmektedir (8). Solunumsal ve kardiyak nedenlerin mekanizmaları net olmamakla birlikte, ana nedenin periferal kas limitasyonuna bağlı olduğunu gösteren çalışmalar da mevcuttur (5,9). Akciğer nakli uygulanan hastaların çoğunluğu egzersizi bacak yorgunluğuna bağlı olarak sonlandırmaktadır (10). Bir çalışmada, akciğer nakli sonrası egzersiz kapasitesindeki toparlanmanın, greft fonksiyonundaki gecikmiş iyileşme ile değil, kas kuvvetindeki yavaş geri dönüş ile ilişkili olduğu belirtilmiştir (11). Çalışmamızda periferik kas kuvvetinin, fonksiyonel egzersiz kapasitesi üzerine etkisi irdelenmiştir.

“BODE” indeksi, KOAH'ın ağırlı̆̆ını değerlendirmek amacı ile kullanılan 4 farklı parametreden oluşan bir skorlamadır. İndeks, hastaların akciğer nakli için listelenmesinde de klinik pratikte kullanılır (7). Bu indeks içerisinde vücut kitle indeksi, FEV1\% değeri, Modifiye Medical Research Council dispne skoru ve 6-dakika yürüme testi yer almaktadır. İndeksin son sonuç ölçüsünü oluşturan 6-dakika yürüyüş testi, bireylerin kardiyovasküler sağlığının ortaya konmasında ve tedavi etkinliğini ölçmede yaygın olarak kullanılır (12). İndekste, 6 dakika yürüme mesafesi 350 metrenin altında olan değerler için puan aralıkları oluşturulmuştur. Dolayısıyla 350 metre bir "cutoff" mesafe olarak düşünülmektedir. Biz de hasta popülasyonumuzu egzersiz kapasitesine göre gruplandırmak istediğimiz çalışmamızda, 350 metreyi eşik değer olarak kabul ettik.

Tüm olguların 6-dakika yürüme mesafelerine bakıldığında, hastaların yarısından fazlasının 350 metrenin altında yürüme mesafelerinin olduğu görülmektedir. Olguların terminal dönem akciğer hastası olduğu ve akciğer nakli için listelenmiş oldukları göz önünde bulundurulduğunda, bu durum literatürle uyumludur (13).

Kronik obstruktif akciğer hastalarında, quadriceps femoris (QF) kas gücünün mortalite ve hastane başvuru oranlarıyla ilişkili olduğuna dair çalışmalar bulunmaktadır $(14,15)$. İngiliz Toraks Cerrahisi (BTC) kllavuzunda, egzersiz programı ile QF kas gücünün arttığına dair kanıt düzeyi “+1"dır. Yüz sekiz akciğer nakil adayı üzerinde yapılmıș olan bir çalışmada periferik kas kuvvetinin 6-dakika yürüme mesafesinin bir prediktörü olabileceği, QF kuvvetlendirme egzersizlerinin PR programları içerisine dahil edilmesi gerektiği vurgulanmıștır (4). Çalıșma fikrimizin çıkıș noktası bu bilgidir. Çalışmamızda, gruplar arası karşılaştırmada sadece dorsifleksiyon kas kuvvetinde farklılık vardı. Yaptığımız korelasyon analizinde ise egzersiz kapasitesi, dirsek fleksiyonu ve dorsifleksiyon ile ilişkili bulundu. Dirsek fleksiyonu, genel kas kondüsyonunun belirteçlerinden biri olabileceği şeklinde yorumlanabilir. Diğer taraftan egzersiz kapasitesini etkileme potansiyeli yüksek olan alt ekstremite kas kuvvetinin tüm parametreleri ile bir bağlantı kurulamaması, sadece dorsifleksiyonun ilişkili bulunması ilginç bir sonuçtur. 


\begin{tabular}{|c|c|c|c|c|c|c|c|c|c|c|c|c|}
\hline & $\begin{array}{c}\text { Kas } \\
\text { kütlesi }\end{array}$ & $\begin{array}{l}\text { Yağsız } \\
\text { doku\% }\end{array}$ & $\begin{array}{c}\text { Yağ } \\
\text { kütlesi }\end{array}$ & Yă̆\% & Yaş & BKİ & Diz ext & DirsekF & KK & DF & FEV1\% & FVC\% \\
\hline \multicolumn{13}{|c|}{ 6DYM } \\
\hline $\mathbf{r}$ & 193 & ,192 & ,257 & ,229 &,- 187 & ,310 & ,368 & ,483* & ,179 &, $518^{* *}$ &, $514^{* *}$ &, $605^{* *}$ \\
\hline $\mathbf{p}$ & ,356 & ,358 & ,215 & ,270 & ,370 & ,131 & 071 & ,015 & ,392 & ,008 & ,009 & ,001 \\
\hline
\end{tabular}

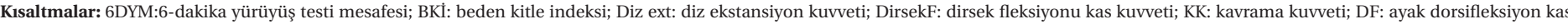
kuvveti; FEV1: 1.saniyedeki ekspiratuar volüm. Kas kuvvetlerinde dominant ekstremite baz alınmıştır. *p<,005; **p<,01.

Vücut kompozisyonu ve özellikle kas kütlesi, fiziksel fonksiyonları etkileyen parametrelerdir. KOAH’lılar üzerinde yapılan bir çalışmada normal, sarkopenik ve obez sarkopenik hasta gruplarının egzersiz kapasitesi, solunum ve periferik kas kuvvetleri karşılaştırılmış, obez sarkopenik grubun fiziksel fonksiyonlarının daha kötü olduğu ve kas kütlesinin fiziksel statüyü etkilediği sonucu çıkartılmıştır (16). Bekleme listesindeki akciğer nakil adaylarında yapılan bir çalışmada, 6-dakika yürüme mesafesinin mortalite ile bağımsız olarak korele olduğu ve bu mesafenin, beslenme belirteçlerinden olan vücut yağ kütlesi ve bacak kas kütlesinden etkilendiği ortaya konmuştur (17). Kalp nakli sonrasında egzersiz kapasitesi değişiminin bağlı olduğu faktörlerin incelendiği başka bir çalışmada ise, yeterli oksijen tüketim seviyesine ulaşılmasına etki eden faktörlerin daha ziyade periferik faktörler olduğu, düşük vücut yağ yüzdesi ve yüksek kas kütlesinin egzersiz kapasitesi üzerine olumlu etkisinden bahsedilmektedir (18). Çalışmamızda, beklenenin aksine kas kütle ve yüzdesi gruplar arasında benzer olup, egzersiz kapasitesi ile kas kütle ve yüzdesi arasında bir ilişki bulunamamıştır. Bu durum, hastaların terminal dönem akciğer hastaları olmaları ve solunum fonksiyonlarının ileri seviyede bozulmuş olmalarından kaynaklanabilir. Nitekim çalışmamızda, yürüme mesafesi düşük olan grubun FEV1 değerinin de diğer gruba göre düşük olduğu ve solunum fonksiyonları ile yürüme mesafesi arasında orta seviyede bir korelasyon olduğu tespit edilmiştir.

Gruplararası karşılaştırmada dorsifleksiyon kas kuvveti, gruplar arasında istatistiksel olarak anlamlı düzeyde farklı çıkmıştır. Bu hasta grubunda kas kuvveti kaybının olması beklenen bir durumdur ve nakil öncesi dönemde de belirgindir (19). Çalışmamızda yürüyüş mesafesi fazla olan grubun dorsifleksör kas kuvveti de fazladır. Başka bir deyişle, periferik kas kuvveti yürüme mesafesini etkileyebilir. Stroke hastalarında yapılan bir çalışmada, alt ekstremite kas kuvveti ile 6-dakika yürüme mesafesinin arasında pozitif yönde bir ilişki bulunmuştur (20). Akciğer nakil adaylarında, periferik kas kuvveti ve egzersiz kapasitesi ilişkisini farklı hasta grupları üzerinde inceleyen bir çalışmada, tüm hasta gruplarında 6-dakika yürüme mesafesinin, beklenen değerlerle karşılaştırılmasında düşük olduğu ortaya konmuştur (19). Yine aynı çalışmada, triceps ve biceps kuvvetlerinin beklenen değerleri ile karşılaştırılmasında, so- nuçların alt ekstremite kas kuvvetinin aksine \%60 ile \%91 arasında olduğu rapor edilmiştir (19). Çalışmamızda egzersiz kapasitelerine göre ayrılan gruplarda, gruplar arasında farklı çıkan parametre dorsifleksiyon kas kuvveti olmuştur. Korelasyon analizinde ise egzersiz kapasitesinin, dorsifleksiyon ve dirsek fleksiyon kas kuvvetiyle ilişkili olduğu bulunmuştur. Hasta grubumuzun genel klinik durumları göz önünde bulundurulduğunda, üst ekstremite kas kuvvetinin de düşük olması beklenen bir sonuç olmakla birlikte, egzersiz kapasitesi ile ilişkili bulunması ilginçtir.

Kısıtlılıklar: Çalışmamız retrospektif bir çalışmadır. Kişi sayısı göreceli olarak azdır ve daha çok erkek hastalardan oluşmaktadır. Kişi sayısının azlığı dolayısıyla hastalık bazlı altgrup analizi yapılamamıştır.

Çalışmamızdan elde edilen verilere göre egzersiz kapasitesi, periferik kas kuvvetinden kısmen etkilenmektedir. Bu durum, egzersiz kapasitesindeki azalışın, primer olarak solunum fonksiyonlarındaki kötüleşmeden kaynaklanabileceğini düşündürmektedir. Egzersiz programlarının yer aldığı randomize kontrollü çalışmalara ihtiyaç vardır.

\section{KAYNAKLAR}

1. Kugler C, Gottlieb J, Warnecke G, et al. Health-related quality of life after solid organ transplantation: a prospective, multiorgan cohort study. Transplantation 2013; 96:316-323

2. Spruit MA, Singh SJ, Garvey C, et al. An official American Thoracic Society/European Respiratory Society statement: key concepts and advances in pulmonary rehabilitation. Am J Respir Crit Care Med 2013; 188:e13-64

3. Mathur S, Hornblower E, Levy RD. Exercise training before and after lung transplantation. Phys Sportsmed 2009; 37:78-87

4. van Adrichem EJ, Reinsma GD, van den Berg S, et al. Predicting 6-minute walking distance in recipients of lung transplantation: longitudinal study of 108 patients. Phys Ther 2015; 95:720-729

5. Reinsma GD, ten Hacken NH, Grevink RG, et al. Limiting factors of exercise performance 1 year after lung transplantation. J Heart Lung Transplant 2006; 25:1310-1316

6. Falque L, Gheerbrant H, Saint-Raymond C, et al. [Selection of lung transplant candidates in France in 2019]. Rev Mal Respir 2019; 
$36: 508-518$

7. Pirard L, Marchand E. Reassessing the BODE score as a criterion for listing COPD patients for lung transplantation. Int J Chron Obstruct Pulmon Dis 2018; 13:3963-3970

8. Mathur S, Reid WD, Levy RD. Exercise limitation in recipients of lung transplants. Phys Ther 2004; 84:1178-1187

9. Maury G, Langer D, Verleden G, et al. Skeletal muscle force and functional exercise tolerance before and after lung transplantation: a cohort study. Am J Transplant 2008; 8:1275-1281

10. Dudley KA, El-Chemaly S. Cardiopulmonary exercise testing in lung transplantation: a review. Pulm Med 2012; 2012:237852

11. Walsh JR, Chambers DC, Davis RJ, et al. Impaired exercise capacity after lung transplantation is related to delayed recovery of muscle strength. Clin Transplant 2013; 27:E504-511

12. Rasekaba T, Lee AL, Naughton MT, et al. The six-minute walk test: a useful metric for the cardiopulmonary patient. Intern Med J 2009; 39:495-501

13. Pehlivan E, Balci A, Kilic L, et al. Preoperative Pulmonary Rehabilitation for Lung Transplant: Effects on Pulmonary Function, Exercise Capacity, and Quality of Life; First Results in Turkey. Exp Clin Transplant 2018; 16:455-460
14. Swallow EB, Reyes D, Hopkinson NS, et al. Quadriceps strength predicts mortality in patients with moderate to severe chronic obstructive pulmonary disease. Thorax 2007; 62:115-120

15. Decramer M, Gosselink R, Troosters T, et al. Muscle weakness is related to utilization of health care resources in COPD patients. Eur Respir J 1997; 10:417-423

16. Machado FVC, Schneider LP, Fonseca J, et al. Clinical impact of body composition phenotypes in patients with COPD: a retrospective analysis. Eur J Clin Nutr 2019

17. Oshima A, Nishimura A, Chen-Yoshikawa TF, et al. Nutritionrelated factors associated with waiting list mortality in patients with interstitial lung disease: A retrospective cohort study. Clin Transplant 2019:e13566

18. Nytroen K, Rustad LA, Gude E, et al. Muscular exercise capacity and body fat predict VO(2peak) in heart transplant recipients. Eur J Prev Cardiol 2014; 21:21-29

19. Van Der Woude BT, Kropmans TJ, Douma KW, et al. Peripheral muscle force and exercise capacity in lung transplant candidates. Int J Rehabil Res 2002; 25:351-355

20. Pradon D, Roche N, Enette L, et al. Relationship between lower limb muscle strength and 6-minute walk test performance in stroke patients. J Rehabil Med 2013; 45:105-108 